\title{
Flunarizine induces Nrf2-mediated transcriptional activation of heme oxygenase-1 in protection of auditory cells from cisplatin
}

\author{
H-S So ${ }^{1,5}$, H-J Kim $^{1,5}$, J-H Lee ${ }^{1}$, J-H Lee ${ }^{1}$, S-Y Park ${ }^{1}$, C Park ${ }^{1}$, \\ Y-H Kim ${ }^{1}$, J-K Kim ${ }^{1}$, K-M Lee ${ }^{2}$, K-S Kim², S-Y Chung, \\ W-C Jang ${ }^{3}$, S-K Moon ${ }^{4}$, H-T Chung ${ }^{1}$ and R-K Park ${ }^{*, 1}$ \\ ${ }^{1}$ Vestibulocochlear Research Center \& Department of Microbiology, Wonkwang \\ University School of Medicine, Jeonbuk 570-749, Korea \\ 2 Division of Biological Sciences, Chonbuk National University, Jeonbuk 561- \\ 756 , Korea \\ 3 Department of Surgery, Chonnam National University School of Medicine, \\ Chonnam 501-746, Korea \\ ${ }^{4}$ Gonda Department of Cell and Molecular Biology, House Ear Institute, Los \\ Angeles, CA, USA \\ 5 The authors were equally contributed to this work. \\ * Corresponding author: R-K Park, Department of Microbiology, Wonkwang \\ University School of Medicine, 344-2 Shinyong-dong Iksan, Jeonbuk 570-749, \\ Korea (South). Tel: + 8263850 6777; Fax: + 8263852 0220; \\ E-mail: rkpark@wonkwang.ac.kr
}

Received 27.10.05; revised 12.12.05; accepted 19.12.05; published online 17.2.06 Edited by M Oren

\begin{abstract}
We investigated the cytoprotective mechanisms of flunarizine in cisplatin-induced death of auditory cells. Concomitant with an increase in viability, treatment with flunarizine resulted in a marked dissociation of Nrf2/Keap1 and subsequent intranuclear translocation of Nrf2, which was mediated by PI3K-Akt signaling. Overexpression of Nrf2 protected cells from cisplatin along with transcriptional activation of ARE to generate heme oxygenase-1 (HO-1). Pretreatment with flunarizine predominantly increased the transcriptional activity of HO-1 among Nrf2-driven transcripts, including HO-1, NQ01, GCLC, GCLM, GST $\mu-1$, and GSTA4. Furthermore, both pharmacological inhibition and siRNA transfection of $\mathrm{HO}-1$ completely abolished the flunarizine-mediated protection of HEI-OC1 cells and the primary rat (P2) organ of Corti explants from cisplatin. These results suggest that Nrf2-driven transcriptional activation of ARE through PI3K-Akt signaling augments the generation of HO-1, which may be a critically important determinant in cellular response toward cisplatin and the cytoprotective effect of flunarizine against cisplatin. Cell Death and Differentiation (2006) 13, 1763-1775. doi:10.1038/sj.cdd.4401863; published online 17 February 2006
\end{abstract}

Keywords: Ototoxicity; Nrf-2; nuclear translocation; heme oxygenase-1; ARE; auditory cells

Abbreviations: ROS, reactive oxygen species; wt-Nrf, wild type Nrf2; DN-Nrf2, dominant negative Nrf2; CoPPIX, Cobalt protoporphyrin IX; SnPPIX, tin protoporphyrin IX; HO-1, heme oxygenase-1
Introduction

Antioxidant response element (ARE) is a cis-acting regulatory element in promoter regions of several genes encoding phase II detoxification enzymes and antioxidant proteins, such as $\mathrm{NAD}(\mathrm{P}) \mathrm{H}$ :quinine oxidoreductase-1 (NQO1), glutathione S-transferase (GST), $\gamma$-glutamylcysteine synthetase $(\gamma$-GCS), heme oxygenase 1 (HO-1), thioredoxin reductase-1, and thioredoxin. ${ }^{1}$ Transcriptional activation through ARE is mainly regulated by NF-E2-related factor 2 (Nrf2), a member of Cap'n'Collar (CNC) family of transcription factors that share a highly conserved basic region-leucine zipper (bZIP) structure. ${ }^{2}$ Nrf2 is abundantly expressed in liver, intestine, lung and kidney, where detoxification reactions occur routinely. Recently, Nrf2 and its downstream proteins have been shown to be critically important regulators in protection of cells from oxidative stress- and chemicalinduced damages of liver and lung tissues. Chan et al. ${ }^{3}$ reported that Nrf2 protects liver from acetaminophen-induced injury and lung tissues from butylated hydroxyltoluleneinduced toxicity. ${ }^{4}$ Cho et al. ${ }^{5}$ demonstrated that Nrf2 knockout mice are more sensitive to hyperoxic injury of lung. The primary astrocyte of $\mathrm{Nrf}^{-/-}$mice is also more susceptible to oxidative stress and inflammation than that of $\mathrm{Nrf}^{+/+}$mice. ${ }^{6}$ Leung et $a l^{7}$ showed that deficiency of Nrf2 results in early embryonic lethality with severe oxidative stress. These observations, collectively, imply that Nrf2 is a master regulator of ARE-driven transcriptional activation for antioxidant genes in maintaining the homeostasis of Redox status within cells.

Heme oxygenase $(\mathrm{HO})$ is a rate-limiting enzyme in heme catabolism, which finally leads to the generation of bilirubin, free iron, and carbon monoxide (CO). Three mammalian $\mathrm{HO}$ isoforms have been identified, one of which, $\mathrm{HO}-1$, a stressresponsive protein, could be induced by various oxidative agents through Nrf2-mediated transcriptional activation of ARE. In recent years, several groups have investigated the functions of $\mathrm{HO}-1$, usually by observing the ability of cells to resist from various stress insults when $\mathrm{HO}-1$ is under- or overexpressed. These studies have supported the designation as an important cellular defense role for $\mathrm{HO}-1$ against oxidant injury. ${ }^{8}$

Cisplatin (cis-diaminedichloroplatinum II; CDDP) is one of extensively used chemotherapeutic agents in treatment of various solid tumors. ${ }^{9}$ However, serious side effects of cisplatin, including progressive, irreversible sensorineural hearing loss and tinnitus, greatly impair the quality of life. Ototoxicity due to cisplatin occurs primarily in cochlea, especially in the outer hair cells (OHCs) of organ of Corti. ${ }^{10}$ However, the exact mechanisms of cisplatin ototoxicity still remain to be elusive. Recently, many evidences have been accumulated to demonstrate that ototoxicity of cisplatin is closely related to the increased production of reactive oxygen 
species (ROS) and aberrant adduction of its metabolite into the nucleus. ${ }^{11}$

Flunarizine is an antagonist of T-type specific calcium channels, $\mathrm{CACN} \alpha 1 \mathrm{G}$ and $\mathrm{CACN} \alpha 1$, which permit calcium entry into cells. Clinically, flunarizine is known as Sibelium ${ }^{\mathrm{TM}}$ and has been widely used to treat the clinical disorders, including vertigo, migraine, epilepsy, and tinnitus. ${ }^{12}$ Recently, it is known to protect the perfused rat liver cells from ischemia with reperfusion and neurons from serum deprivation, nerve growth factor deprivation, oxidative stress, and axotomy, respectively. ${ }^{13}$ Previously, we reported that flunarizine attenuated the cisplatin-induced apoptosis of auditory cells through inhibition of lipid peroxidation and mitochondrial permeability transition. Herein, we further demonstrate that flunarizine stimulates Nrf2-driven transcriptional activation of ARE through PI3K-Akt signaling and thereby increase the generation of $\mathrm{HO}-1$, which plays a crucial role in protection of auditory cells from cisplatin.

\section{Results}

\section{Flunarizine protected $\mathrm{HEI}-\mathrm{OC} 1$ auditory cells from cisplatin}

In previous study, we already demonstrated that cisplatin induced the apoptotic death of HEI-OC1 auditory cells, evidenced by nuclear condensation, DNA laddering and caspase-3 activation. ${ }^{14}$ However, pretreatment with flunarizine completely abolished the characteristic apoptotic features caused by cisplatin. In this experiment, we measured the viability of $\mathrm{HEI}-\mathrm{OC} 1$ cells by MTT assay after treatment with $20 \mu \mathrm{M}$ cisplatin for $48 \mathrm{~h}$ in the presence or absence of $10 \mu \mathrm{M}$ flunarizine. As shown in Figure 1, treatment with cisplatin decreased the viability up to $44 \%$ at $20 \mu \mathrm{M}$ cisplatin. However, pretreatment with flunarizine significantly protected cells from cisplatin as represented an increase in viability up to 82 from $44 \%$ in cells treated with cisplatin-alone $(n=3$, $P<0.05$ by One-Way ANOVA).

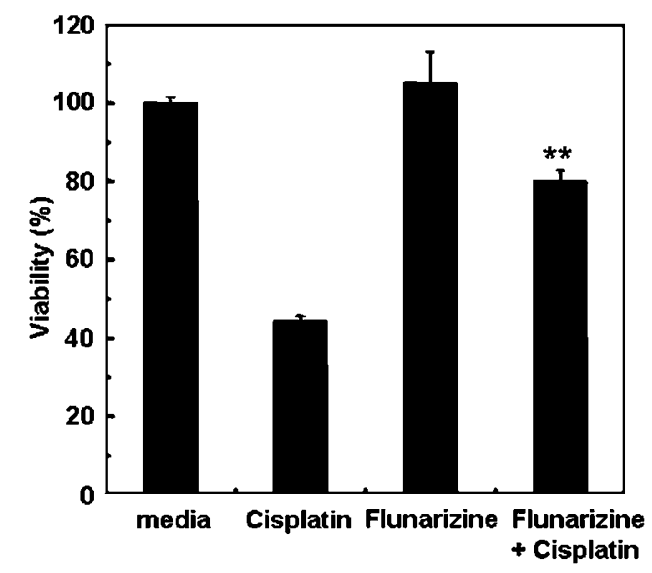

Figure 1 Pretreatment with flunarizine resulted in an increase of viability in cisplatin-treated HEI-OC1 cells. Cells were pretreated with $10 \mu \mathrm{M}$ flunarizine for $30 \mathrm{~min}$ and followed by the addition of $20 \mu \mathrm{M}$ cisplatin for $36 \mathrm{~h}$. Cell viability was measured by MTT assay. The data represent the mean \pm S.D. of three independent experiments. ${ }^{* \star} P<0.01$ by one-way ANOVA, compared with only cisplatin-treated group

\section{Flunarizine dramatically increased the nuclear translocation of Nrf2 via PI3K-Akt signal pathway}

In previous study, we showed that cisplatin increased the generation of ROS in $\mathrm{HEI}-\mathrm{OC} 1$ cells. ${ }^{14}$ Many studies have also shown that Nrf2 plays as a pivotal defense element against oxidative stresses within cells. ${ }^{7}$ Therefore, we questioned whether flunarizine affects the expression and localization of Nrf2 in cisplatin-treated cells. To address this question, we first examined the subcellular localization of Nrf2 in HEI-OC1 cells. Immunostaining analyses demonstrated that Nrf2 predominantly presented in the cytoplasm of control cells (Figure 2b). A small proportion of Nrf2 protein moved into the nucleus after treatment of cisplatin alone, even though a majority of the protein still remained in the cytoplasm (Figure 2e). However, the majority proportion of Nrf2 translocated into the nucleus following a single treatment with flunarizine (Figure $2 \mathrm{~h}$ and $\mathrm{i}$ ). Furthermore, pretreatment with flunarizine alone predominantly confined Nrf2 protein into the nucleus in cisplatin-treated cells (Figure $2 \mathrm{k}$ and I).

To further validate this phenomenon, cells were treated with $20 \mu \mathrm{M}$ cisplatin in the presence or absence of $10 \mu \mathrm{M}$ flunarizine and cell lysate was fractionated into cytoplasmic and nuclear parts to carry out the Western blot for Nrf2. As shown in Figure 3a, Nrf2 was predominantly located in the cytoplasm of the control cells whereas it was not detectable in the nuclear fraction. Single treatment with cisplatin alone further increased the nuclear translocation of Nrf2 into the nucleus along with decrease in the intensity of Keap 1 band in cytosolic fraction. However, pretreatment with flunarizine alone induced the pronounced nuclear translocation of Nrf2 concomitant with marked decrease in the expression level of Keap 1 in cytosolic fraction. Consistently, Nrf2 in the cytoplasmic fraction was significantly decreased shown as a faint band in cells treated with flunarizine and cisplatin. Also, the cytosolic expression of Keap1 was markedly decreased to an almost undetectable level after treatment with flunarizine and cisplatin (Figure 3a). We measured the VDAC expression to verify the right procedure for nuclear extract preparation and equal amount loading in Western blotting analysis. Recently, several signaling pathways, including MAPKs and $\mathrm{PI} 3 \mathrm{~K},{ }^{15}$ have been implicated in the nuclear translocation and activation of Nrf2. Therefore, to further elucidate the mechanisms by which flunarizine induces the nuclear translocation of Nrf2, we examined the effect of flunarizine on MAPKs, including $\mathrm{JNK},{ }^{16}$ ERK and $\mathrm{p} 38,{ }^{17}$ and PI3K-Akt kinase. The phosphorylation of JNK, ERK and p38 proteins was not apparent in cells treated with flunarizine alone. On the contrary, cisplatin time-dependently induced the activation of three MAPKs, which was markedly antagonized by pretreatment with flunarizine (data not shown, manuscript in preparation). However, flunarizine apparently increased the phosphorylation of Akt in a time-dependent fashion. Maximal intensity of the immunoreactive band of phosphorylated Akt was observed $1 \mathrm{~h}$ after treatment with flunarizine alone (Figure 3b). Furthermore, pharmacological inhibition of PI3K using specific inhibitors, including LY294002 and wortmannin, markedly abrogated the protective effect of flunarizine against cisplatin in MTT assay (Figure 3c). We further confirmed that the flunarizine-induced nuclear translocation of Nrf2 was 

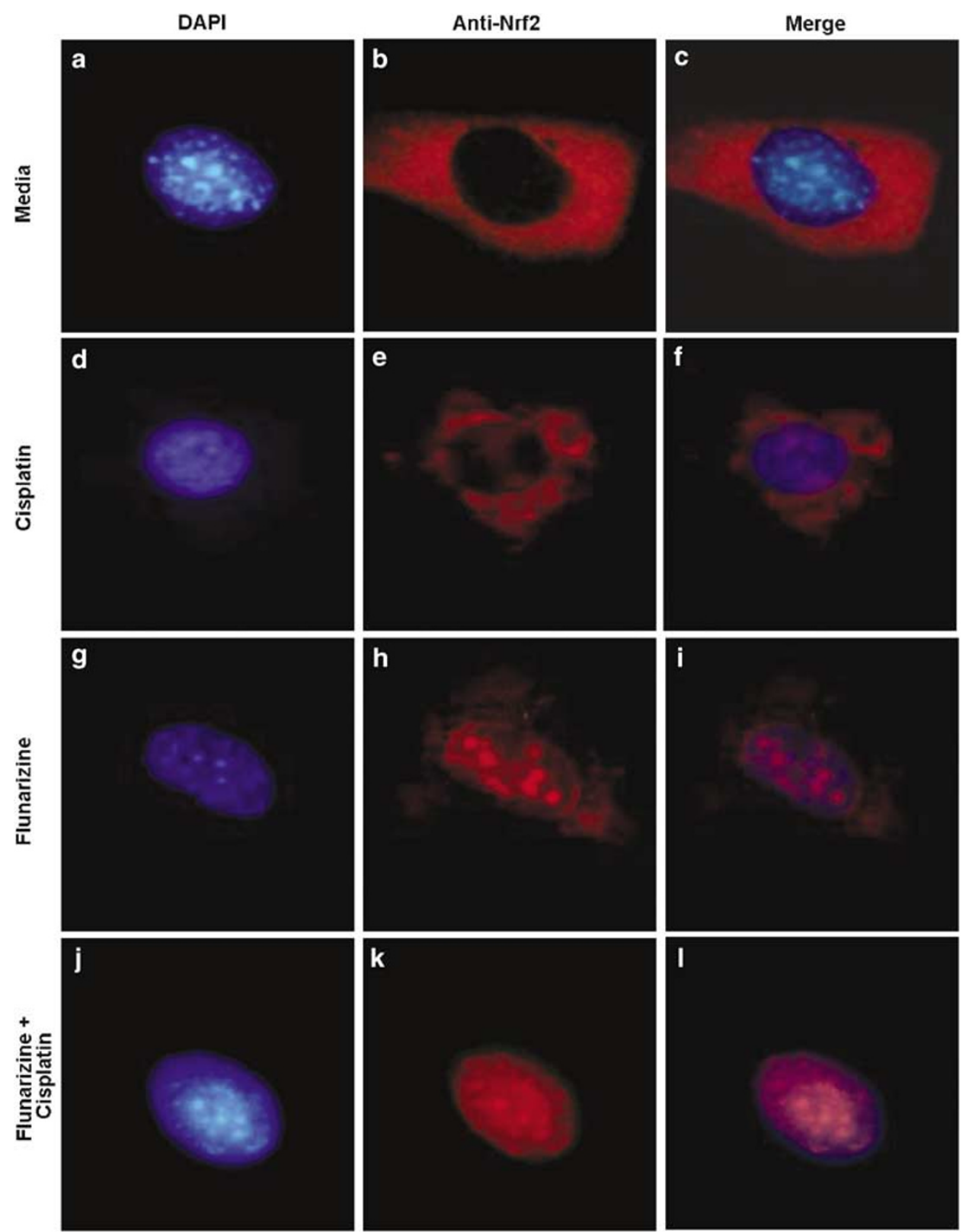

Figure 2 Pretreatment with flunarizine induced the nuclear translocation of Nrf2. Cells were treated with $20 \mu \mathrm{M}$ cisplatin for $6 \mathrm{~h}$ in the presence or absence of $10 \mu \mathrm{M}$ flunarizine. After reaction with DAPI and anti-Nrf2 antibody, cells were visualized under fluorescent microscope

markedly suppressed by treatment with PI3K specific inhibitors, including LY294002 and wortmannin (Figure 3d). These results suggest that flunarizine induces the nuclear translocation of Nrf2 via the PI3K-Akt signaling, but not by MAPKs pathway in HEI-OC1 cells.

\section{Ectopic expression of WT-Nrf2 rendered HEI-OC1 cells to be more resistant against cisplatin}

To further elucidate the functional role, the expression vectors of Nrf2, including wild-type Nrf2 (WT-Nrf2) and dominant negative Nrf2 (DN-Nrf2), were transiently introduced into $\mathrm{HEI}$ $\mathrm{OC} 1$ cells. The competence of ectopic expression of two Nrf2
DNA constructs showed that transfection with two Nrf2 constructs, including WT-Nrf2 and DN-Nrf2, increased the translational levels of the protein according to the amounts of each plasmid DNAs used, respectively. Next, to determine whether ectopic expression of Nrf2 modulates the transcriptional activity of ARE-driven luciferase reporter gene, cells were co-transfected Nrf2 plasmids with ARE-luciferase reporter construct (ARE-Luc), containing the enhancer 2 and minimal promoter region of mouse HO-1. ARE-Luc assays in transfectants demonstrated that overexpression of WT-Nrf2 significantly increased ARE-driven luciferase activity in a dose-dependent manner, whereas the ectopic expression of DN-Nrf2 suppressed the transcriptional activity of ARE-Luc (Figure 4b). After successful establishment of ARE-Luc 
a

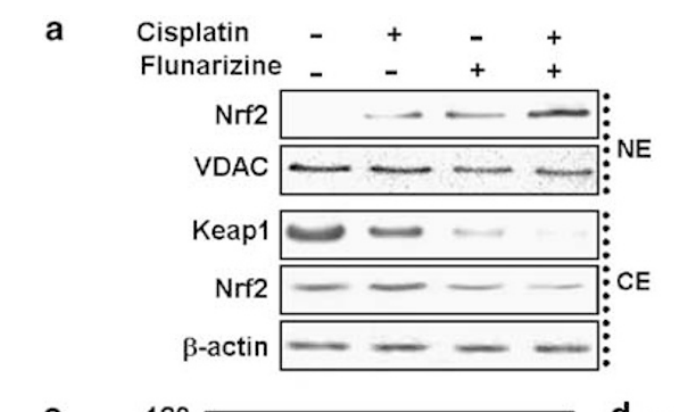

b

。

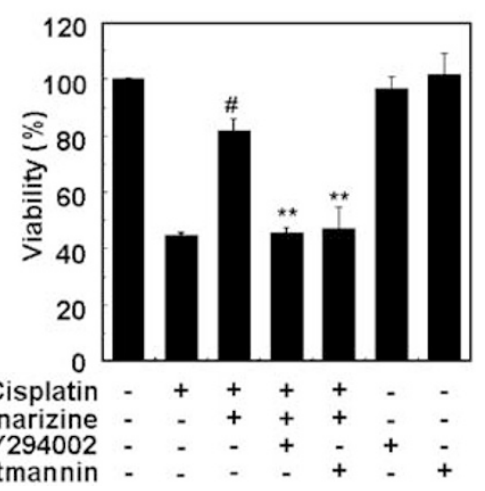

Figure 3 The nuclear translocation of Nrf2 was mediated by PI3K-Akt signal in flunarizine-treated cells. (a) Cells were treated with $20 \mu \mathrm{M}$ cisplatin for $12 \mathrm{~h}$ in the presence or absence of $20 \mu \mathrm{M}$ flunarizine. Cytosolic (CE) and nuclear (NE) extracts from cells were separated on $12 \%$ SDS-PAGE to probe Nrf2, Keap-1, VDAC, and $\beta$ actin by Western blot. The equal amount of protein loaded was confirmed by the expression levels of VDAC and $\beta$-actin. (b) Cells were incubated with $20 \mu \mathrm{M}$ flunarizine for indicated time periods. Western blot was performed using specific antibodies for phospho-Akt and Akt. (c) Cells were pretreated with $10 \mu \mathrm{M} \mathrm{LY} 294002$ or $1 \mu \mathrm{M}$ wortmannin for $30 \mathrm{~min}$ and followed by the addition of $20 \mu \mathrm{M}$ cisplatin in the presence of $10 \mu \mathrm{M}$ flunarizine for $36 \mathrm{~h}$. Cell viability was measured by MTT assay. ${ }^{\#} P<0.01$, ${ }^{* *} P<0.01$ by one-way ANOVA, compared with only cisplatin-treated group (\#), or cisplatin/flunarizine-treated group $\left({ }^{* *}\right)$ (d) Cells were treated with $20 \mu \mathrm{M}$ cisplatin, $10 \mu \mathrm{M}$ flunarizine or cisplatin/flunarizine for $12 \mathrm{~h}$ in the presence of $10 \mu \mathrm{M}$ LY204002 or $1 \mu \mathrm{M}$ wortmannin. Cytosolic (CE) and nuclear (NE) extracts from cells were immunoblotted for Nrf2, VDAC, and $\beta$-actin

reporter gene assay, we tested whether the ectopic expression of WT-Nrf2 modulates the susceptibility of HEI-OC1 cells toward cisplatin. Overexpression of WT-Nrf2 alone dose-dependently rendered cells to be more resistant against cisplatin (Figure 4c). However, ectopic expression of DN-Nrf2 did not affect the survival of $\mathrm{HEI}-\mathrm{OC} 1$ cells in the presence of cisplatin. We further confirmed that ARE-Luc activity was significantly increased by overexpression of WT-Nrf2 whereas that was decreased by transfection of DN-Nrf2 in the presence of cisplatin (Figure 4d). These data indicate that Nrf2-driven transcriptional activation of ARE may provide one aspect of critical defense functions of $\mathrm{HEI}-\mathrm{OC} 1$ cells from cisplatin.

\section{Flunarizine required the Nrf2-driven transcriptional activation of ARE in protection of cells from cisplatin}

Next, we investigated whether Nrf2-driven transcriptional activation of ARE was directly involved in eliciting the protective effect of flunarizine against cisplatin. Cells were transfected with DN-Nrf2 plasmid and followed by the addition of $20 \mu \mathrm{M}$ cisplatin in the presence of $10 \mu \mathrm{M}$ flunarizine for $36 \mathrm{~h}$. As shown in Figure $5 \mathrm{a}$, the cytoprotective effect of flunarizine was dose-dependently suppressed according to increasing amounts of DN-Nrf2 plasmid transfected in cisplatin-treated cells. In parallel with this observation, pretreatment with flunarizine significantly increased the ARE-driven luciferase activity, which was markedly suppressed by ectopic expression of DN-Nrf2 plasmid in a dose-dependent fashion (Figure 5b). We also confirmed that transfection of DN-Nrf2 plasmid dose-dependently inhibited the enzymatic activation of $\mathrm{HO}-1$ by flunarizine in cisplatin-treated cells (data not shown). These results suggest that Nrf2-driven transcriptional activation of ARE is critically needed in the protective effect of flunarizine against cisplatin.

\section{Nrf2-mediated HO-1 activation was required in protective effect of flunarizine against cisplatin}

Both ectopic expression of WT-Nrf2 plasmid and treatment with flunarizine could increase the transcriptional activity of ARE-driven luciferase, which containing the minimal promoter region of mouse HO-1 gene. These results imply the possibility that one of the products of the transcriptional activation of ARE, including HO-1, may function as a protective regulator against cisplatin in $\mathrm{HEI}-\mathrm{OC} 1$ cells. To address this question, we measured the expression level of HO-1 protein in stable transfectants of WT-Nrf2 and DN-Nrf2 plasmids. As shown in Figure 6a, overexpression of WT-Nrf2 derived a marked increase in expression level of $\mathrm{HO}-1$ protein compared to the parental cells as well as transfectants of pcDNA3 and DN-Nrf2 plasmids. Consistent with the expression level of HO-1 protein, the enzymatic activity 


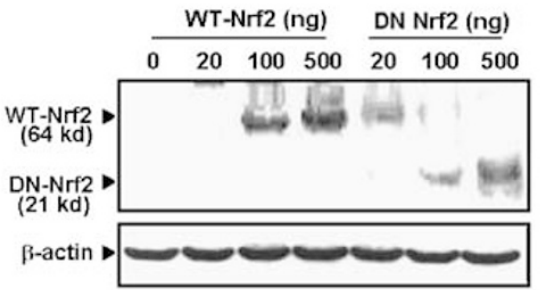

C

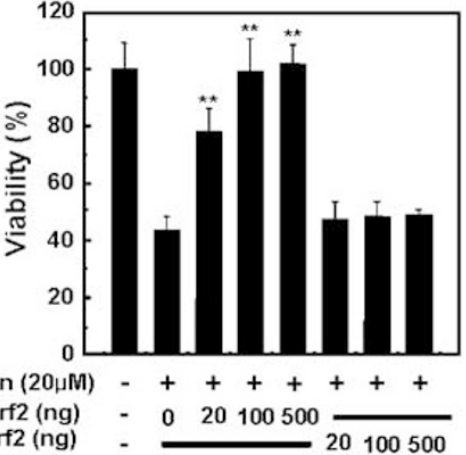

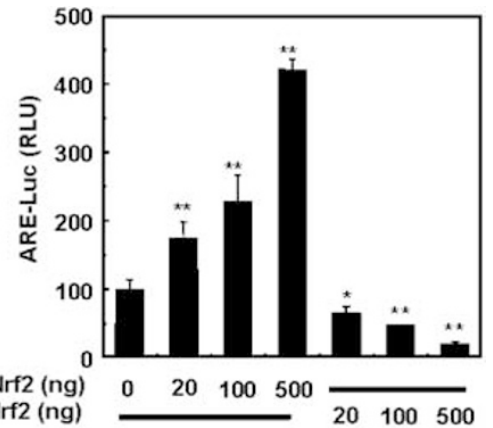

d

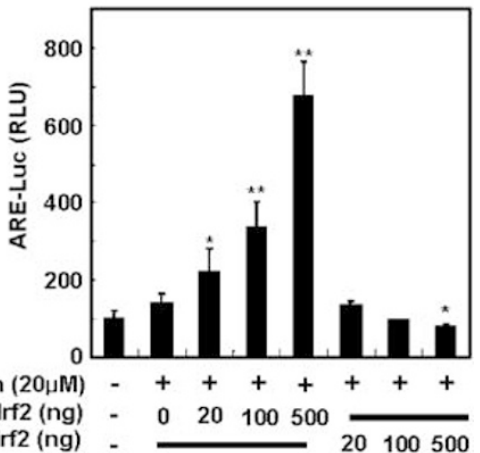

Figure 4 Ectopic expression of WT-Nrf2 rendered HEl-OC1 cells more resistant against cisplatin. (a) After $48 \mathrm{~h}$ later, expression levels of WT-Nrf2 or DN-Nrf2 protein were measured by Western blotting using anti-Nrf2 antibody. (b) Cells were co-transfected with Nrf2 expression vectors and ARE-luciferase reporter gene for $24 \mathrm{~h}$, and then luciferase activity was measured at $18 \mathrm{~h}$ later. ${ }^{*} P<0.05,{ }^{\star \star} P<0.01$ by one-way ANOVA, compared with control group. (c) Cells were treated with $20 \mu \mathrm{M}$ cisplatin for $36 \mathrm{~h}$ and the viability was measured by MTT assay. (d) Cells were cotransfected with Nrf2 expression vectors and ARE-luciferase reporter gene for $24 \mathrm{~h}$, and then further treated with $20 \mu \mathrm{M}$ cisplatin for $18 \mathrm{~h}$, and then luciferase activity was measured. ${ }^{\star} P<0.05$, ${ }^{\star *} P<0.01$ by one-way ANOVA, compared with only cisplatin-treated group (c, d)

a

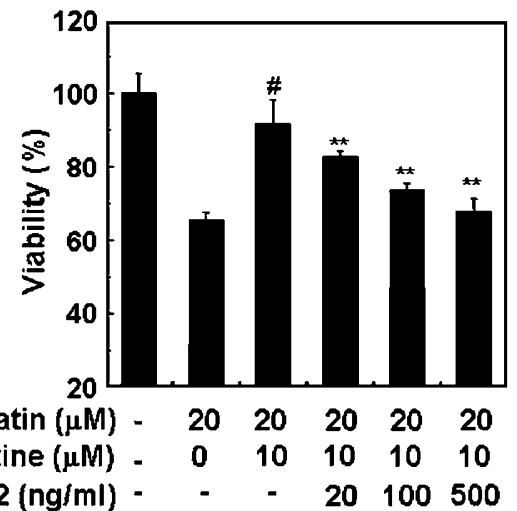

b

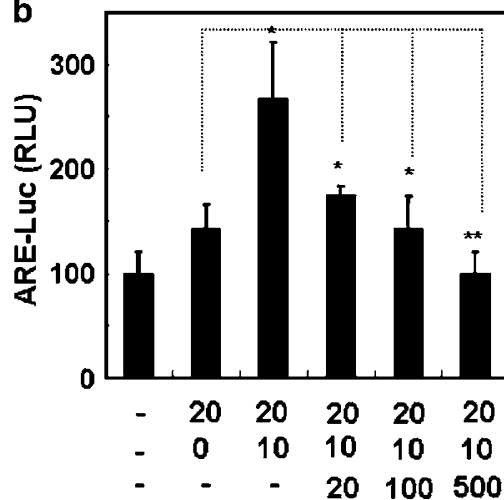

Figure 5 Pretreatment with flunarizine required the transcriptional activity of Nrf2 to elicit the protective effect against cisplatin. (a) Cells were transfected with various doses of DN-Nrf2 expression vector and were followed by the addition of cisplatin in the presence of flunarizine for $36 \mathrm{~h}$ to measure the cell viability by MTT assay. (b) Cells, co-transfected with ARE-Luc reporter gene and DN-Nrf2 expression vector, were treated with $20 \mu \mathrm{M}$ cisplatin in the presence of $10 \mu \mathrm{M}$ flunarizine for $18 \mathrm{~h}$, and then luciferase activity was measured. ${ }^{\#} P<0.01,{ }^{*} P<0.05,{ }^{*} P<0.01$ by one-way ANOVA, compared with only cisplatin treated group $\left({ }^{\#}\right)$ or flunarizine/cisplatincotreated group $\left({ }^{*},{ }^{* *}\right)$

of HO-1 was significantly increased in WT-Nrf2 transfectant $(2259 \pm 135 \mathrm{pmol}$ bilirubin/mg protein/h) compared to pcDNA3 transfectant $(223 \pm 5 \mathrm{pmol} / \mathrm{bilirubin} / \mathrm{mg}$ protein $/ \mathrm{h}, \quad P<0.001)$ (Figure 6b)

We next tested whether $\mathrm{HO}-1$ affects the viability of Nrf2 transfectants in the presence of cisplatin. Overexpression of WT-Nrf2 plasmid alone was sufficiently enough to render cells to be resistant against cisplatin (Figure $6 \mathrm{c}) \quad(P<0.01$ compared to pcDNA3 transfectant, one-way ANOVA). However, DN-Nrf2 plasmid could not induce resistance against cisplatin. Furthermore, we examined the effect of cobaltprotoporphyrin IX (CoPPIX), a HO-1 inducer, ${ }^{18}$ on the viability of transfectants in the presence of cisplatin. Treatment with CoPPIX significantly increased the viability of cells 
a
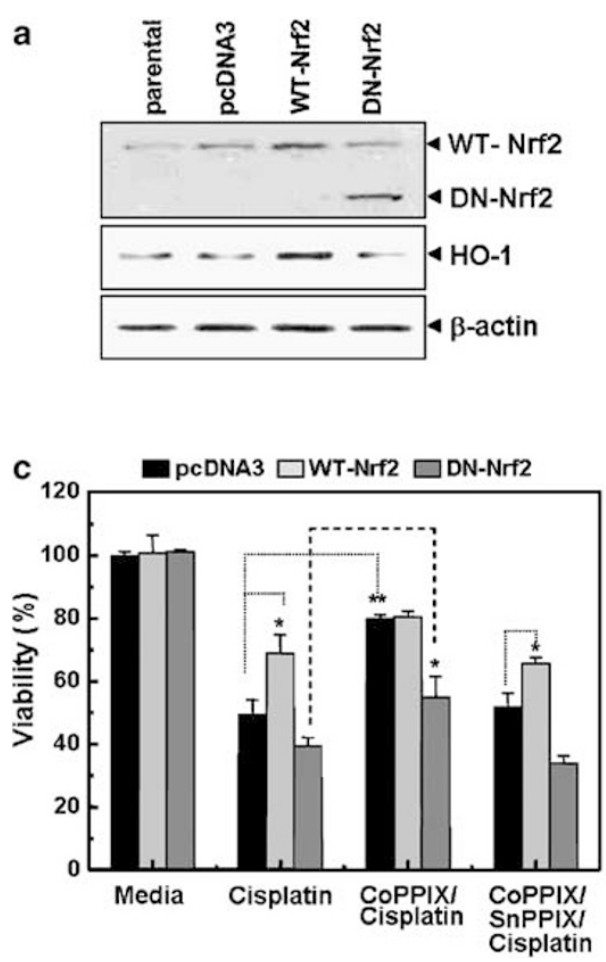

b

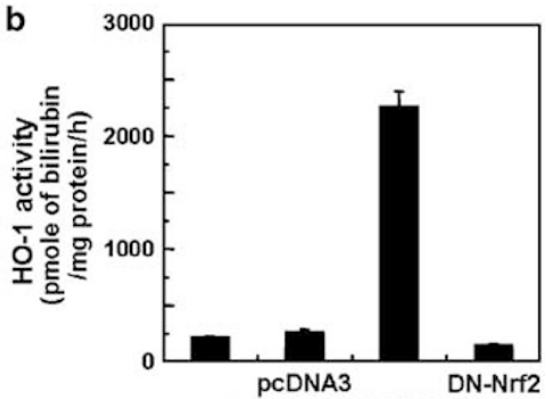

d

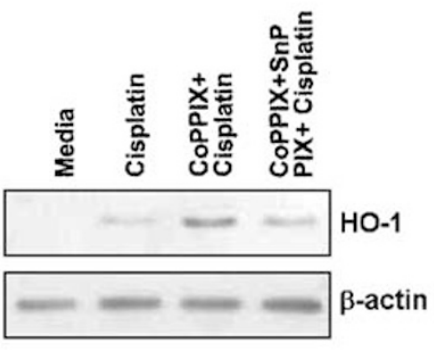

Figure 6 Ectopic expression of Nrf2 increased the survival of cells via induction of HO-1. (a) Transfectants of WT-Nrf2 or DN-Nrf2 were used to measure the expression levels of Nrf2 and $\mathrm{HO}-1$ protein by Western blotting. (b) The enzymatic activity of $\mathrm{HO}-1$ from transfectants was determined by measuring bilirubin formation (c) Transfectants of Nrf2 constructs were treated with cisplatin for $36 \mathrm{~h}$ in the presence or absence of $20 \mu \mathrm{M}$ CoPPIX, and then cell viability was measured by MTT assay. ${ }^{*} P<0.05,{ }^{*} P<0.01$ by one-way ANOVA. (d) After treatment with $20 \mu \mathrm{M}$ CoPPIX in the presence cisplatin for $24 \mathrm{~h}, \mathrm{HO}-1$ expression of parental HEI-OC1 cells was measured by Western blotting

transfected with pcDNA3, WT-Nrf2 and DN-Nrf2 plasmids $(P<0.05$ or 0.01 , compared to pcDNA3 transfectant treated with cisplatin only, one-way ANOVA). However, suppression of HO-1 activity by cotreatment with SnPPIX, an inhibitor of HO-1 enzymatic activity, markedly abolished the protective effect of CoPPIX in parent cells as well as in two transfectants of Nrf2, including WT-Nrf2 and DN-Nrf2 (Figure 6c). Interestingly, Wt-Nrf2 transfectant was still significantly resistant to cisplatin $(P<0.01$, compared to pcDNA3 transfectant) in the presence of SnPPIX. We further confirmed that pretreatment with CoPPIX increased the expression of $\mathrm{HO}-1$ protein (Figure 6d).

To further rule out the roles of other Nrf2-driven transcriptional activation, the mRNA expression profiles of a plethora of genes regulated by Nrf2 were examined by RT-PCR amplification from cells treated with cisplatin alone, flunarizine alone, or combination of cisplatin and flunarizine for $24 \mathrm{~h}$ (Figure 7a). Treatment with cisplatin alone could induce an early transcriptional activation of various Nrf2-driven mRNAs, including HO-1, NQO1, GCLC, GCLM, GST $\mu-1$, and GSTA4, at 1 or $3 \mathrm{~h}$ after treatment. Interestingly, pretreatment with flunarizine predominantly induced much earlier and augmented expression of HO-1 mRNA only among other Nrf2-driven transcripts. Flunarizine-mediated augmentation of the transcriptional activation of $\mathrm{HO}-1$ remained up to $24 \mathrm{~h}$ in the presence of cisplatin. However, transcriptional activation of other Nrf2-driven transcripts, including as NQO1, GCLC, GCLM, GST $\mu$-1, and GSTA4, in cisplatin-treated cells was not changed regardless in the presence of flunarizine.
To define the role of $\mathrm{HO}-1$ in the protective effect of flunarizine from cisplatin cytotoxicity, cells were also pretreated with SnPPIX to suppress HO-1 activity in the presence of cisplatin and flunarizine (Figure $7 \mathrm{~b}$ ). The data demonstrated that treatment with flunarizine significantly increased the viability of cisplatin-treated cells, which was dose-dependently alleviated by pretreatment with SnPPIX. We also verified that pretreatment with flunarizine resulted in a marked increase of enzymatic activity of $\mathrm{HO}-1$ activity, which was also markedly suppressed by the addition of SnPPIX, respectively (Figure 7c). In addition, induction of HO-1 protein by pretreatment with flunarizine was also slightly reduced by the addition of SnPPIX (Figure 7d). In our previous study, we demonstrated that another T-type calcium channel blocker, pimozide, also showed the cytoprotetive effect against cisplatin-mediated HEI-OC1 auditory cell deaths. ${ }^{14}$ We, therefore, verified the effects of other calcium channel brokers, including nicardipine, nifedipine, diltiazem, flunarizine and pimozide, on $\mathrm{HO}-1$ induction by Western blot. As shown in Figure $7 \mathrm{e}$, both pimozide and flunarizine could markedly induce $\mathrm{HO}-1$ proteins in $\mathrm{HEI}-\mathrm{OC} 1$ cells.

Next, to further make sure that the protective effect of flunarizine is indeed mediated through Nrf2/HO-1 activation, the siRNA constructs of Nrf2 and HO-1 were transfected in $\mathrm{HEI}-\mathrm{OC} 1$ cells. Knockdown the transcriptional expressions of $\mathrm{Nrf} 2$ and $\mathrm{HO}-1$ by using siRNAs revealed that activation of both Nrf2 and HO-1 signaling was obligatory required in the protective effect of flunarizine against cisplatin. Transfection of either Nrf2 or HO-1 siRNAs, but not unrelated control 


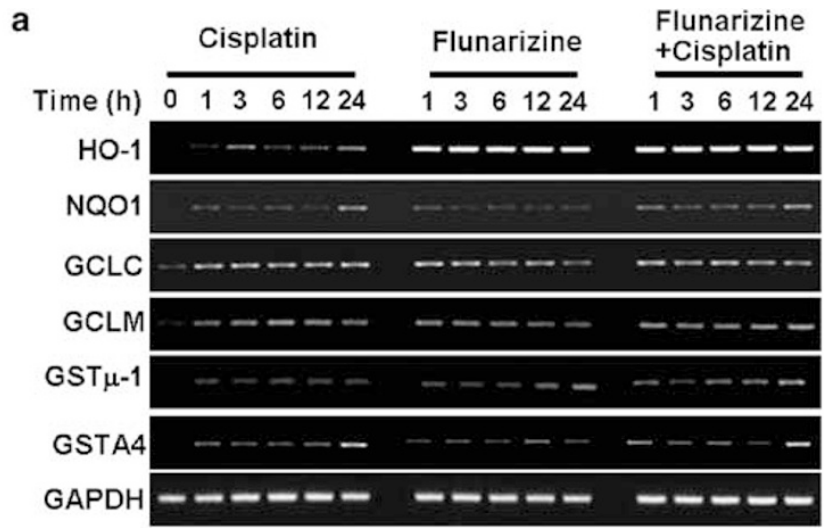

b

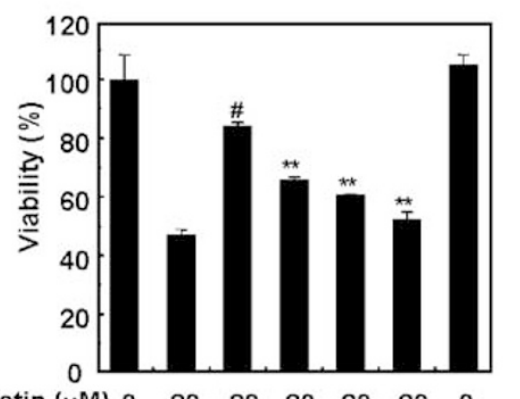

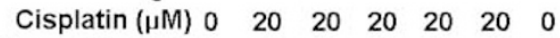

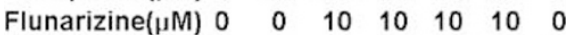

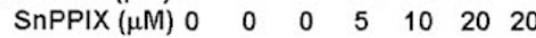

d

Cisplatin $(\mu \mathrm{M}) \quad 0 \quad 20 \quad 20 \quad 20 \quad 20 \quad 20 \quad 0$

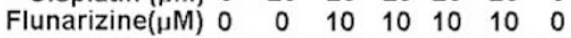

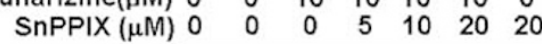

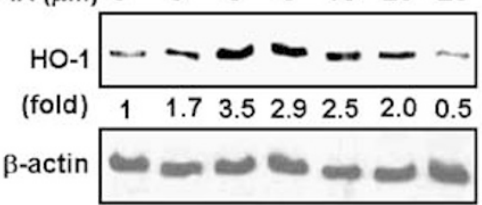

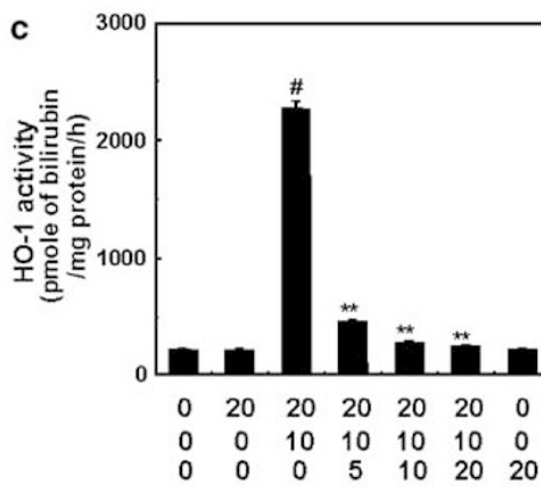

e

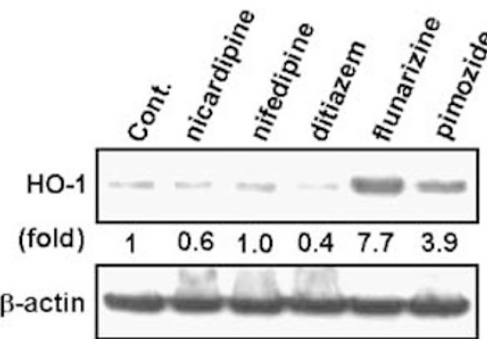

Figure 7 Pretreatment with flunarizine predominantly induced the transcriptional expression of HO-1 among other Nrf2-regulated genes in cisplatin-treated cells. (a) Cells were treated with $20 \mu \mathrm{M}$ cisplatin for the indicated periods in the presence or absence of $10 \mu \mathrm{M}$ flunarizine. Then, total RNA was isolated by RNAzol and cDNA was synthesized by reverse transcriptase. The Nrf2-related genes, including HO-1, NQ01, GCLC, GCLM, GST $\mu$-1, and GSTA4, were amplified with specific primer sets, respectively. Also, cells were treated with $20 \mu \mathrm{M}$ cisplatin, $10 \mu \mathrm{M}$ flunaizine and various doses of SnPPIX for $36 \mathrm{~h}$ and used to measure the cell viability (b), to determine the enzymatic activity of $\mathrm{HO}-1$ at $20 \mathrm{~h}(\mathbf{c})$, or to test the expression level of $\mathrm{HO}-1$ protein by Western blotting (d). ${ }^{*} P<0.01$, ${ }^{* *} P<0.01$ by one-way ANOVA, compared with only cisplatin treated group (\#) or flunarizine/cisplatin-cotreated group $\left(^{*},{ }^{* *}\right)$. (e) To examine the effect of calcium channel blockers on the HO- 1 induction, cells were treated with various calcium channel blockers for $24 \mathrm{~h}$. Cell lysates were separated on $12 \%$ SDS-PAGE to probe for HO-1 and $\beta$-actin by Western blot. Nicardipine, $10 \mu \mathrm{M}$; nifedipine, $12.5 \mu \mathrm{M}$; ditiazem, $10 \mu \mathrm{M}$; pimozide, $2.5 \mu \mathrm{M}$

siRNAs, resulted in a substantial suppression of cell viability in cells treated with flunarizine and cisplatin (Figure 8a). We confirmed that transfection of Nrf2 or $\mathrm{HO}-1$ siRNAs curtailed the expression of their respective mRNAs (Figure $8 \mathrm{~b}$ ). Moreover, consistent with previous results, expression of $\mathrm{HO}-1$ mRNA completely disappeared following transfection of Nrf2 SiRNA.

Next, to further examine the mechanism by which end metabolites of heme catabolism by $\mathrm{HO}-1$, including bilirubin, iron, and carbon monoxide (CO), contribute to the cellular resistance against cisplatin in $\mathrm{HEI-OC1}$ cells, cells were incubated with CO-releasing agent CO-RM2, bilirubin, and ferric citrate before the addition of cisplatin (Figure $8 \mathrm{c}$ ). The data showed that pretreatment with $\mathrm{CO}-\mathrm{RM} 2$ and bilirubin resulted in a significant increase in viability of cisplatin-treated cells. However, treatment with ferric citrate, as an iron donor, failed to protect cells from cisplatin (Figure 8c).

As the inhibition of PI3K using specific inhibitors, including LY294002 and wortmannin, markedly abrogated the nuclear translocation of Nrf2 as well as the protective effect of flunarizine against cisplatin (Figure $3 c$ and d), we further examined the effect of PI3K inhibition on $\mathrm{HO}-1$ induction by flunarizine. In parallel with the inhibition of nuclear translocation of Nrf2 by PI3K inhibitors, $\mathrm{HO}-1$ induction by flunarizine was apparently inhibited by pretreatment with PI3K inhibitors, including LY294002 and wortmannin (Figure 9). These results suggest that flunarizine indeed regulates $\mathrm{HO}-1$ expression through PI3K/Nrf2 signaling. 
a

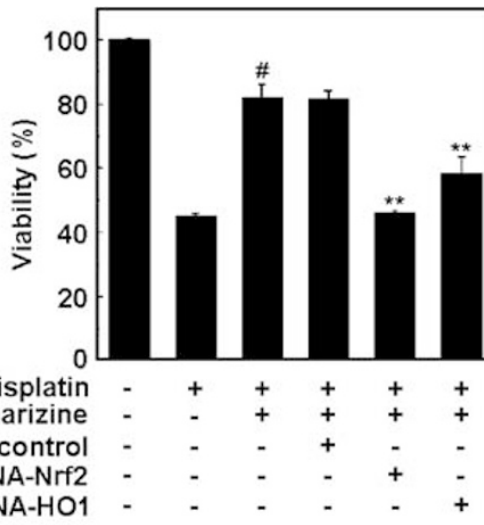

b
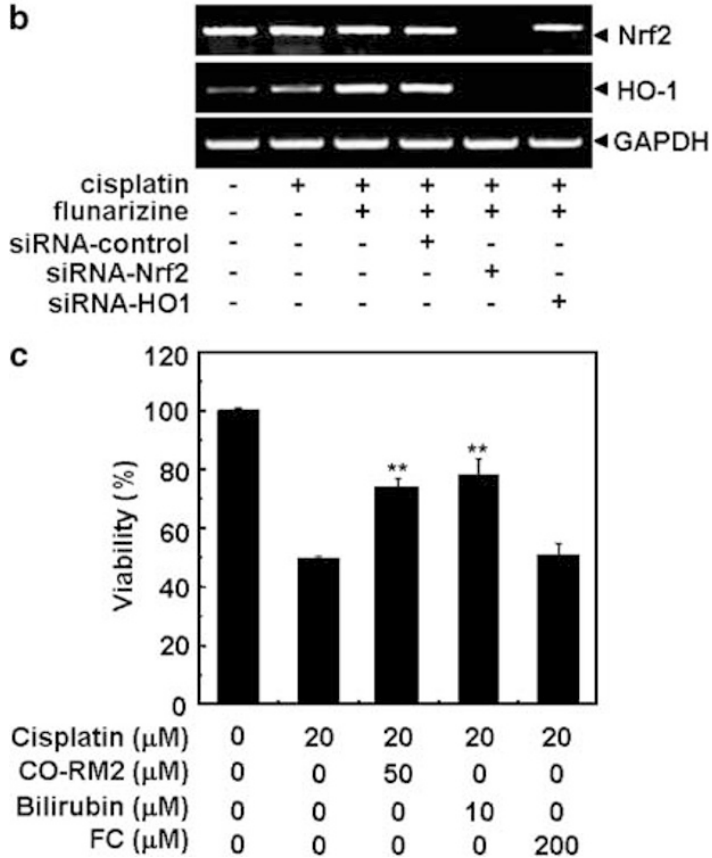

Figure 8 Knock down of both Nrf2 and HO-1 by siRNA transfection abolished the protective effect of flunarizine against cisplatin in $\mathrm{HEI}-\mathrm{OC} 1$ cells. Cells were transfected with $0.5 \mu \mathrm{g}$ siRNAs constructs of $\mathrm{Nrf} 2, \mathrm{HO}-1$, and control plasmid and further treated with $20 \mu \mathrm{M}$ cisplatin and $10 \mu \mathrm{M}$ flunarizine. (a) Cell viability was measured by MTT assay at $36 \mathrm{~h}$ after treatment. ${ }^{\#} P<0.01$, ${ }^{\star} P<0.01$ by oneway ANOVA, compared with only cisplatin-treated group $(\#)$, or cisplatin/ flunarizine-treated group (**). (b) After $24 \mathrm{~h}, \mathrm{RT}$-PCR was performed to amplify Nrf2 and HO-1 genes. (c) Cells were treated with $20 \mu \mathrm{M}$ cisplatin for $36 \mathrm{~h}$ in the presence of CO-RM2 $(50 \mu \mathrm{M})$, bilirubin $(10 \mu \mathrm{M})$, and ferric citrate (FC) $(200 \mu \mathrm{M})$. Cell viability was measured by MTT assay. ${ }^{* *} P<0.01$ by one-way ANOVA, compared with only cisplatin-treated group

\section{Protective effect of flunarizine on the primary organ of Corti explants}

Finally, to examine whether flunarizine protects the primary organ of Corti explants from cisplatin, the half middle turn of organ of Corti from neonatal (P2) Sprague-Dawley rats was isolated and treated with $10 \mu \mathrm{M}$ flunarizine and $20 \mu \mathrm{M}$ cisplatin for $25 \mathrm{~h}$ in the presence or absence of $10 \mu \mathrm{M}$ SnPPIX. Media control alone did not induce apparent damage on stereocilia bundles, of which F-actin was intensely labeled with TRITCconjugated phalloidin (Figure 10a). Three rows of $\mathrm{OHCs}$ and a single row of IHCs were clearly observed in phalloidin staining

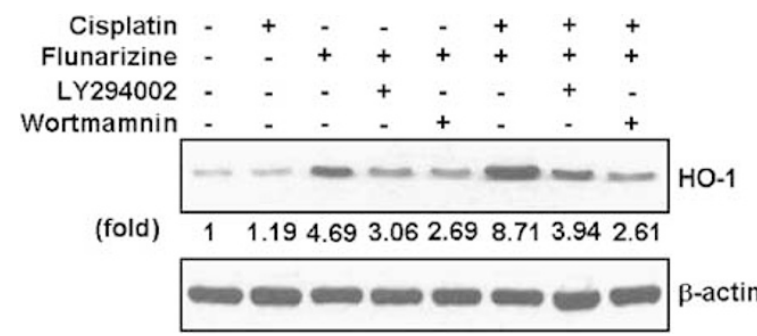

Figure 9 Pharmacologic inhibition of PI3K decreased the flunarizine-mediated induction of HO-1 in HEl-OC1 cells. Cells were treated with $20 \mu \mathrm{M}$ cisplatin, $10 \mu \mathrm{M}$ flunarizine or cisplatin/flunarizine for $12 \mathrm{~h}$ in the presence of PI3K inhibitors, including $10 \mu \mathrm{M} \mathrm{LY} 204002$ and $1 \mu \mathrm{M}$ wortmannin. Cell lysates were separated on $12 \%$ SDS-PAGE and immunoblotted for $\mathrm{HO}-1$ and $\beta$-actin
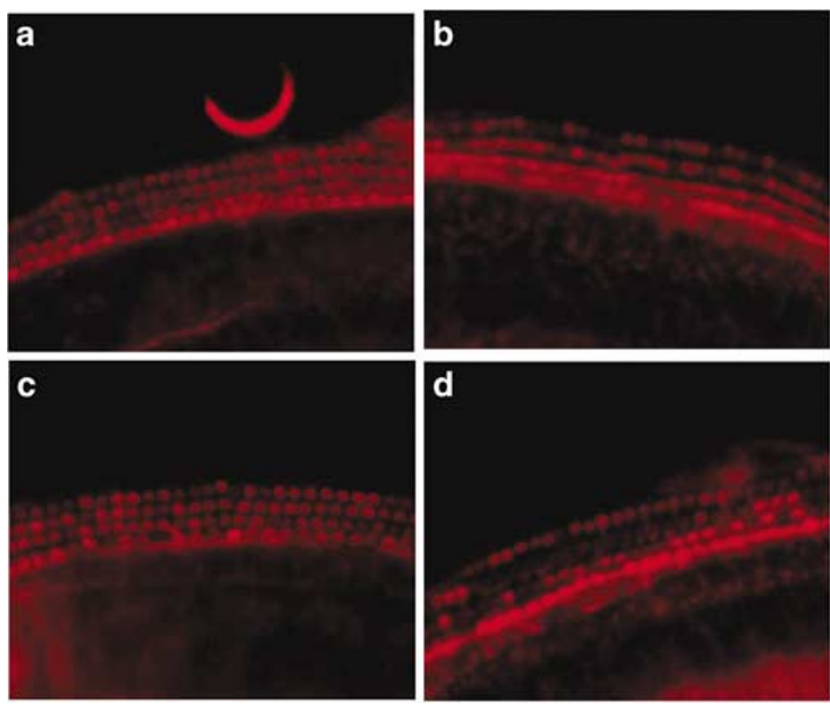

Figure 10 Pharmacologic inhibition of $\mathrm{HO}-1$ activity suppressed the protective effect of flunarizine against cisplatin in the rat primary organ of Corti explants. The organ of Corti explants were treated with media (a), $20 \mu \mathrm{M}$ cisplatin (b), $10 \mu \mathrm{M}$ flunarizine plus cisplatin (c), or triple combination with cisplatin, flunarizine, and $10 \mu \mathrm{M}$ SnPPIX for $28 \mathrm{~h}$. The organ of Corti explants were stained with TRITCconjugated phalloidin, and then observed under fluorescent microscope

of media control group. Treatment with cisplatin resulted in destruction of stereocilia bundles, and caused the disarray of three rows of OHCs and a single row of IHCs (Figure 10b). However, pretreatment with flunarizine apparently provided a complete protection against cisplatin-induced stereocilia loss in the primary organ of Corti explants (Figure 10c). However, the pharmacological inhibition of $\mathrm{HO}-1$ activity by SnPPIX markedly abolished the protective effect of flunarizine on the primary rat organ of Corti explants from cisplatin (Figure 10d).

\section{Discussion}

Cisplatin is one of the most widely used chemotherapeutic agents in treatment of human tumors, but the risk of ototoxicity and nephrotoxicity commonly hampers the use of higher doses to maximize its antineoplastic effects. ${ }^{19}$ Ototoxicity following cisplatin therapy is common, and is a result of damage to $\mathrm{OHCs}$ of the organ of Corti. ${ }^{20,21}$ In fact, cisplatin 
induces apoptosis of OHCs in the organ of Corti explants and in vivo. It is also well known that cytotoxicity of cisplatin occurs via at least two major mechanisms, including formation of DNA adducts ${ }^{22-24}$ and damage due to ROS generation. ${ }^{20,25}$ Ultimately, these processes lead auditory organs to lose functional components by apoptosis or necrosis. ${ }^{26,27}$

Recently, we reported that flunarizine, an antagonist of T-type specific calcium channels $\mathrm{CACN} \alpha 1 \mathrm{G}$ and $\mathrm{CACN} \alpha 1$, protects auditory cells from cisplatin through inhibition of lipid peroxidation and mitochondrial dysfunction. ${ }^{14}$ In the present study, we have further elucidated that $\mathrm{Nrf} / \mathrm{HO}-1$ signaling is directly involved in the protective effect of flunarizine against cisplatin in both $\mathrm{HEI}-\mathrm{OC}$ auditory cells and in the primary rat $\mathrm{P}(2)$ organ of Corti explants.

Nrf2 is a basic leucine zipper transcription factor, which transcriptionally regulates many genes including $\mathrm{HO}-1,{ }^{28}$ $\mathrm{NAD}(\mathrm{P}) \mathrm{H}$ :quinine oxidoreductase-1 (NQO-1), ${ }^{29} \gamma$-glutamylcysteine synthase, ${ }^{30}$ and glutathione $S$-transferase. Inactive Nrf 2 is localized in the cytoplasm, in part or totally, as a consequence of binding to cytoskeleton-associated protein, Keap1. ${ }^{31}$ Recently, it has also been reported that MAP kinases, including ERKs, JNKs, and p38, are implicated in phosphorylation and stabilization of Nrf2 to facilitate its nuclear translocation ${ }^{32}$ and binding to distinct but very similar DNA elements, individually or alternatively referred to as Maf recognition element (MARE), ${ }^{33}$ stress-response element (StRE) ${ }^{29}$ or antioxidant-response element (ARE). ${ }^{34}$ In addition, PI3K/Akt signaling pathway also regulates AREs activation via the nuclear translocation of Nrf2. ${ }^{15}$

We demonstrated here that Nrf2 is predominantly localized in the cytoplasm of resting cells. However, it apparently translocated into the nucleus following the addition of flunarizine. Treatment with flunarizine resulted in a pronounced increase in nuclear Nrf2 along with a concomitant decrease in cytosolic Nrf2 protein levels. However, flunarizine did not affect the total expression amount of Nrf2 protein within cells. We also detected a concomitant decrease in the total amount of Keap-1 protein, which bound to Nrf2, in the cytosol by the addition of flunarizine. To further provide the exact mechanism how flunarizine induced the nuclear translocation of Nrf2, we examined several signaling pathways, including MAPKs and PI3K. The data demonstrated that PI3K pathway was directly involved in the protective effect of flunarizine against cisplatin as well as the nuclear translocation of Nrf2 by flunarizine. However, considering that PI3K inhibitors partially inhibits nuclear Nrf2 translocation whereas they completely reverse the cytoprotection afforded by flunarizine, there may be other roles of PI3K in an Nrf2-independent manner. Akt serves for cell survival through phosphorylation-mediated protein modification, including inactivation of tumor suppressors and activation of trophic signal cascades. ${ }^{35}$ PI3K/Akt signaling also upregulates transport and metabolism of glucose and amino acids. It also stimulates the activity of translation initiation factors and ribosome biosynthesis. ${ }^{36}$ Recently, Abdul-Ghani et al. ${ }^{37}$ reported that inhibition of PI3K results in an increase of intracellular doxorubicin concentration in a competitive manner. Furthermore, flunarizine might induce a loss of PTEN function, which used to trigger the activation of the PI3K/Akt pathway. ${ }^{38}$ In addition, cisplatin induced the activation of MAPKs, which was antagonized by flunarizine (data not shown, manuscript in preparation). This result indicated that the activation of MAP kinases is not directly involved in the nuclear translocation of Nrf2 by flunarizine in HEl-OC1 cells. Of note, we observed that cisplatin also induces translocation of Nrf2 into the nucleus. Based on previous reports, showing that cisplatin generates ROS, which further contributes the Nrf2-driven transcriptional activation of ARE, we could assume that ROS generated by cisplatin induces the nuclear translocation of Nrf2. However, we are confident that the functional role of nuclear translocation of Nrf2 by either ROS or unidentified factors was not sufficient for survival of cells from cisplatin cytotoxicity.

In addition, the intracellular calcium $\left(\left[\mathrm{Ca}^{2+}\right]_{\mathrm{i}}\right)$ levels increased by flunarizine also did not affect the translocation of Nrf2 (data not shown). Our previous data demonstrated that both flunarizine and cisplatin increase $\left[\mathrm{Ca}^{2+}\right]_{i}$ in auditory cells, ${ }^{14}$ Furthermore, an intracellular $\mathrm{Ca}^{2+}$ chelator, BAPTA-AM, and a calcium ionophore, A23187, did not affect the cytotoxicity of cisplatin as well as the protective effect of flunarizine.

$\mathrm{HO}-1$ functions as an important protective regulator against various oxidative injuries ${ }^{39}$ and is also induced by a variety of cellular stress including heme, ${ }^{40}$ hyperoxia, ${ }^{41}$ hypoxia, ${ }^{42}$ and eletrophiles ${ }^{43}$ through transcriptional activation of AP-1, STAT and Nrf2. Many studies have reported that $\mathrm{HO}-1$ expression is mainly regulated by Nrf2-dependent ARE activation in several cell types. ${ }^{44-46}$ Studies of the ectopic expression of Nrf2 and siRNA constructs of $\mathrm{Nrf} 2$ and $\mathrm{HO}-1$ further confirmed that the protective effect of flunarizine is indeed through Nrf2/HO-1 in cisplatin-treated cells. Our results also suggest that the AREdriven upregulation of $\mathrm{HO}-1$ gene expression after treatment with flunarizine was mediated by nuclear translocation of $\mathrm{Nrf2}$, not by de novo synthesis of Nrf2 in $\mathrm{HEI}-\mathrm{OC} 1$. We further understand that there may be other means of transcriptional activation, including AP-1 and STAT, to accelerate $\mathrm{HO}-1$ generation in cisplatin-treated HEl-OC1 cells. Our data demonstrated that CoPPIX, an inducer of HO-1, significantly protected cells against cisplatin in DN-Nrf2 cells even though overexpression of DN-Nrf2 could completely suppress the Nrf2-driven transcriptional activation of ARE-luciferase. However, even though CoPPIX increased the viability of cells treated with cisplatin alone in DN-Nrf2 cells, the protective effect of CoPPIX was not prominent compared to parent cells transfected with pcDNA3 vector only. Furthermore, we observed that CoPPIX triggered the nuclear localization of Nrf2 along with transcriptional activation of ARE-luciferase (data not shown). Similarly, Gong et al. ${ }^{47}$ also reported that cobalt induces $\mathrm{HO}-1$ expression through transcriptional activation of Nrf2. Based on these results, we suggest that the protective effect of CoPPIX against cisplatin is contributed by several factors, including transcriptional activation of Nrf2. Interestingly, transfectant of WT-Nrf2 was still significantly resistant to cisplatin even though the expression and enzymatic activity of $\mathrm{HO}-1$ were markedly suppressed by the addition of SnPPIX. These data suggest that the protective effect of CoPPIX against cisplatin is, in part, mediated by an Nrf2-independent mechanism, which also leads to elicit $\mathrm{HO}-1$ induction.

Besides HO-1 expression, we also considered the possibility that other end products of the transcriptional activation of 
Nrf2 may contribute the cytoprotective effects of flunarizine in cisplatin-treated cells. To address this question, we examined the mRNA expression profiles of a plethora of Nrf2-regulated genes, including HO-1, NQO1, GCLC, GCLM, GST $\mu-1$, and GSTA4, in HEI-OC1 cells. The expression level of $\mathrm{HO}-1$ only was augmented by pretreatment with flunarizine whereas time-dependent mRNA expression profiles of other Nrf2regulated genes, such as NQO1, GCLC, GCLM, GST $\mu-1$, and GSTA4, were not affected by flunarizine in the presence of cisplatin. Therefore, it has still to be elucidated what gene(s) cooperating with $\mathrm{HO}-1$ could confer the significant protective effects of flunarizine against cisplatin in auditory cells. In addition, it is very important to elucidate which metabolic product(s) of HO-1 is responsible for the protective effect of flunarizine in cisplatin-treated cells. In our experiment, exogenous treatment with both bilirubin and carbon monoxide (CO) dose-dependently protected $\mathrm{HEI}-\mathrm{OC} 1$ cells from cisplatin. However, treatment with ferric citrate, as a ferric iron source, failed to protect cells from cisplatin.

In conclusion, we have demonstrated that flunarizine induced the nuclear translocation of Nrf2 and thereby increased mRNA expression of ARE-driven gene, $\mathrm{HO}-1$, through PI3K/Akt activation. Overexpression studies of Nrf2 revealed that Nrf2-driven transcriptional activation of $A R E$ may be a critically important regulator of cellular susceptibility to cisplatin. Also, an increase in enzymatic activity of $\mathrm{HO}-1$ and overexpression of WT-Nrf2 rendered cells to be more resistant against cisplatin in both $\mathrm{HEI}-\mathrm{OC} 1$ and the primary rat $\mathrm{P}(2)$ organ of Corti explants. Taken together, these results suggest that the T-type calcium channel blocker, flunarizine, antagonized the cytotoxicity of cisplatin in auditory cells via activation of PI3K-mediated Nrf2/HO-1 signaling. This Nrf2/ $\mathrm{HO}-1$ signaling may be a potential therapeutic target to prevent ototoxic damage as well as to modulate cellular susceptibility toward cisplatin.

\section{Materials and Methods}

\section{Reagents}

Cisplatin, flunarizine, 3-(4,5-dimethylthiazol-2-yl)-2,5-diphenyl-tetrazolium bromide (MTT), cobalt Protoporphyrin IX (CoPPIX), and tin protoporphyrin IX (SnPPIX), were purchased from Sigma Chemical Co (St Louis, MO). LY294002 and wortmannin were purchased from Calbiochem (La Jolla, $\mathrm{CA})$. For CO supply into cultures, we used DMSO-solubilized CO-RM2 $\left(\left[\mathrm{Ru}(\mathrm{CO})_{3} \mathrm{Cl}_{2}\right]_{2}\right.$, Frontier Scientific Inc., Logan, UT), which was able to release $\mathrm{CO}$ spontaneously into culture medium. Fugene 6 transfection reagent kit was purchased from Roche (Roche diagnostics, Indianapolis, IN). Goat or rabbit anti-Nrf2, anti-HO-1, anti-Keap1, and anti- $\beta$-actin antibodies were purchased from Santa Cruz Biotechnology (Santa Cruz, $\mathrm{CA})$. The plastic culture wares were bought from Becton Dickinson Labware (Franklin Lakes, NJ). Dulbecco's modified essential medium (DMEM), fetal bovine serum (FBS), and other tissue culture reagents were obtained from Life Technologies Inc. (Gaithersburg, MD).

\section{Cell culture and viability}

The establishment and characterization of the conditionally immortalized $\mathrm{HEI}-\mathrm{OC} 1$ cell line was described by Kalinec et al. ${ }^{48}$ Expression of outer hair cell specific markers, including Math1 and Myosin 7a, suggests that
$\mathrm{HEI}-\mathrm{OC} 1$ cells may represent $\mathrm{OHC}$ precursors. ${ }^{49}$ Cells were maintained in high glucose DMEM containing $10 \%$ FBS and $50 \mathrm{U} / \mathrm{ml} \gamma$-interferon (Genzyme, Cambridge, MA). Cells were cultured under permissive conditions: $33^{\circ} \mathrm{C}, 7 \% \mathrm{CO}_{2}$ in DMEM supplemented with $10 \%$ FBS. Cells $\left(3 \times 10^{4}\right.$ cells/each well of 24 -well plate) were incubated with varying concentrations of cisplatin (Sigma) for $36 \mathrm{~h}$. To determine the cell viability, MTT $(0.25 \mathrm{mg})$ was added to $1 \mathrm{ml}$ of cell suspension for $4 \mathrm{~h}$. After three washes of cells with phosphate-buffered saline (PBS, pH 7.4), the insoluble formazan product was dissolved in DMSO. Then, the optical density (OD) of each culture well was measured using a Microplate reader (Titertek Multiskan, Flow Laboratories) at $590 \mathrm{~nm}$. The OD in control cells was taken as $100 \%$ of viability.

\section{Nrf2 plasmid constructs}

WT-Nrf2 and dominant-negative mutant of Nrf2 (DN-Nrf2) were generated by PCR amplification of mouse cDNA with oligonucleotide pairs KpnINrf2: 5'-CGG GGT ACC ATG GAT TTG ATT GAC ATC C-3' and XbalNrf2: 5'TGC TCT AGA CTA GTT TTT CTT TGT ATC TGG-3' and NotlDN-Nrf2: $5^{\prime}$-GCA CGC GGC CGC CAT GGG TGA ATC CCA ATG TGA A-3' and XbalNrf2: 5'-TGC TCT AGA CTA GTT TTT CTT TGT ATC TG-3', respectively. The amplification product was digested by restriction enzymes and cloned into the pcDNA3.1 $(+)$ vector. DN-Nrf2, lacking the transcriptional activation domain, was generated by deleting amino acid residues 1-392 as described previously. ${ }^{28}$

\section{Transfection of Nrf2, HO-1 and siRNAs constructs into $\mathrm{HEI}-\mathrm{OC} 1$ cells}

To generate stable transfectants, cells were transfected with either parental vector, pCDNA3.1, or pcDNA3.1 containing WT-Nrf2 or DN-Nrf2. Stable transfectants were selected after culturing cells in medium containing $400 \mu \mathrm{g} /$ ml of G418 (Invitrogen Corp., Groningen, The Netherlands). Several independent colonies from each transfectant were selected and Nrf2 expression was confirmed by Western blot analysis. Inhibition of $\mathrm{Nif2}$ and $\mathrm{HO}-$ 1 expression was also assessed by Western blotting analysis after transfection of HEl-OC1 cells with Nrf2 and HO-1 siRNA, respectively. The Nrf2 siRNAs construct is a pool of 3 sequences of siRNA as follows: 1170 forward $5^{\prime}$-CUC UGA CUC UGG CAU UUC Att-3'; 1170 reverse 5'-UGA AAU GCC AGA GUC AGA Gtt-3'; 1402 forward 5'-CGU GAA UCC CAA UGU GAA Att-3'; 1402 reverse $5^{\prime}$-UUU CAC AUU GGG AUU CAC GTT-3'; 1826 forward 5'-CCU UGU AUC UUG AAG UCU Utt-3'; 1826 reverse 5'-AAG ACU UCA AGA UAC AAG Gtt-3'. The HO-1 siRNAs is also a pool of three sequences of siRNA as follows: 282 forward $5^{\prime}$-GCU UCC UUG UAC CAU AUC Utt-3'; 282 reverse 5'-AGA UAU GGU ACA AGG AAG Ctt-3'; 745 forward 5' -CCU UCC UGC UCA ACA UUG Att, 745 reverse $5^{\prime}$-UCA AUG UUG AGC AGG AAG Gtt-3'; 1525 forward 5'-CUC UAA CUU CUG UGU GAA Att-3'; 1525 reverse 5'-UUU CAC ACA GAA GUU AGA Gtt-3'. All siRNAs constructs were purchased from Santa Cruz Biotechnology (Santa Cruz, CA).

Briefly, cells were grown in 24-well plates and transiently transfected with $0.5 \mu \mathrm{g}$ of Nrf2, HO-1, or control siRNA constructs mixed with X-tremeGENE siRNA transfection reagent (Roche Applied Science, Penzberg, Germany) according to the manufacturer's protocol. After incubation at $33^{\circ} \mathrm{C}$ and $5 \%$ $\mathrm{CO}_{2}$ for $36 \mathrm{~h}$, cells were further treated with cisplatin and flunarizine. Samples were then prepared and analyzed for viability or RT-PCR.

\section{ARE-luciferase activity assay}

Cells were transfected with ARE-luciferase (ARE-Luc) reporter plasmid. ARE-Luc was generated by transferring the enhancer 2 (E2) and minimal 
promoter (MP) sequence ${ }^{44}$ into luciferase reporter plasmid pGL3-Basic. E2 and MP were generated by PCR of mouse CDNA with oligonucleotide pairs E2 Sacl: 5'-AGC TGA GCT CCT TAA GCA ATC CAT TAG GAA TCC G-3' and E2 Apal: 5'-AGC TGG GCC CCC GCT CTC TTG CCA GAC TC$3^{\prime}$ and MP Apa1: $5^{\prime}-$ TTA CAG GCA GGG CCC GCC T-3' and MP Xho1: $5^{\prime}$-TAT GCT CGA GAC GGC TCT GC-3', respectively. For transfection of reporter plasmid, cells were seeded on 24-well plates at a density of $3 \times 10^{4}$ cells/well on the day before transfection. A total of $750 \mathrm{ng}$ of plasmid DNA including $200 \mathrm{ng}$ of luciferase reporter, various doses of WTNrf2 or DN-Nrf2 expression as noted, and $50 \mathrm{ng}$ of pcDNA3- $\beta$-gal was transfected into cells by $\mathrm{Tfx}^{\mathrm{TM}}-50$ reagent (Promega, Madison, WI). The amount of transfected DNA was held constant to $750 \mathrm{ng}$ by the addition of empty vector DNA where necessary. After $48 \mathrm{~h}$ of transfection, cells were washed twice with PBS buffer and then lysed in reporter lysis buffer. Luciferase activity was measured with a luciferase assay system (Promega) according to the manufacturer's instructions. Luciferase activity was measured in triplicate, averaged, and then normalized with $\beta$-galactosidase activity using the galactosidase assay system (GalactoLight, Tropix Inc., MA) according to the manufacturer's instructions.

\section{Assay for HO-1 activity}

The enzymatic activity of HO-1 was measured by a previously described method. ${ }^{50}$ Briefly, microsomes from harvested cells were added to a reaction mixture containing NADPH, rat liver cytosol as a source of biliverdin reductase and a substrate, hemin. The reaction as conducted at $37^{\circ} \mathrm{C}$ in the dark for $1 \mathrm{~h}$, terminated by the addition of $1 \mathrm{ml}$ of chloroform and extracted bilirubin was calculated by the difference in absorbance between 464 and $530 \mathrm{~nm}$. The protein content was determined by the Lowry method.

\section{Preparation of cytosolic and nuclear extracts}

Cells were washed with ice-cold PBS, scraped, and centrifuged at $1000 \times g$ for $5 \mathrm{~min}$ at $4^{\circ} \mathrm{C}$. The cell pellet was resuspended in $200 \mu \mathrm{l}$ of lysis buffer (10 mM HEPES, pH 7.9, $1.5 \mathrm{mM} \mathrm{MgCl}_{2}, 10 \mathrm{mM} \mathrm{KCl}, 0.5 \mathrm{mM}$ phenylmethylsulfonyl fluoride, and $0.5 \mathrm{mM}$ dithiothreitol) and incubated on ice for $15 \mathrm{~min}$. At the end of this incubation, $10 \mu \mathrm{l}$ of $10 \% \mathrm{NP}-40$ was added and the tube was vortexed for $10 \mathrm{~s}$. After centrifugation at $13000 \times \mathrm{g}$ for 1 min at $4^{\circ} \mathrm{C}$, supernatants (cytosolic extracts) were collected and stored at $-80^{\circ} \mathrm{C}$, whereas the pellets were further processed to obtain nuclear extracts. The pellet was resuspended in extraction buffer ( $5 \mathrm{mM}$ HEPES, $\mathrm{pH} 7.9,1.5 \mathrm{mM} \mathrm{MgCl}, 0.5 \mathrm{mM}$ phenylmethylsulfonyl fluoride, $0.2 \mathrm{mM}$ EDTA, $0.5 \mathrm{mM}$ dithiothreitol, and glycerol $25 \% \mathrm{vol} / \mathrm{vol}$ ) and incubated for $30 \mathrm{~min}$ at $4{ }^{\circ} \mathrm{C}$. Nuclear extracts were isolated by centrifugation at $13000 \times \mathrm{g}$ for $30 \mathrm{~min}$ at $4^{\circ} \mathrm{C}$. The supernatant was aliquoted and stored at $-80^{\circ} \mathrm{C}$ until used for Western blot analysis. Protein concentration was determined by the Lowry method.

\section{Western blot for HO-1and Nrf2}

Western blot was performed as follows. An equal volume of $2 \times$ SDS sample buffer was added and the samples were then boiled for $5 \mathrm{~min}$. Sample $(40 \mu \mathrm{g})$ was subjected to electrophoresis on $12 \%$ SDSpolyacrylamide gels for $2 \mathrm{~h}$ at $20 \mathrm{~mA}$ and then transferred onto nitrocellulose. The membrane was incubated for $1 \mathrm{~h}$ in $5 \%$ (wt/vol) dried milk protein in PBS containing $0.05 \%$ (vol/vol) Tween-20 (PBS-T), washed in PBS-T and then incubated for $1 \mathrm{~h}$ in the presence of primary antibody (1: 1000). The membrane was washed extensively with PBS-T and then incubated with anti-mouse IgG antibody conjugated to $\operatorname{HRP}(1: 3000)$ for 1h. After extensive washes, immunoreactive bands on the membrane were visualized using chemiluminescent reagents according to the manufacturer's protocol (Supersignal Substrate; Pierce, Rockford, IL).

\section{Immunocytochemistry}

Cells were pretreated with $10 \mu \mathrm{M}$ flunarizine and $20 \mu \mathrm{M}$ CoPPIX in the presence or absence of $20 \mu \mathrm{M}$ cisplatin. After removal of the culture medium, cells were washed three times with PBS, and fixed with $4 \%$ paraformaldehyde in PBS for $1 \mathrm{~h}$ at room temperature (RT). Cells were then rinsed twice with PBS, preincubated in the same buffer containing $0.1 \%$ Triton $X-100$, and followed by three washes. Cells were blocked with $0.1 \%$ BSA in PBS for $1 \mathrm{~h}$ and then incubated with primary anti-Nrf2 antibody (SC-13032, Santa Cruz Biotech Inc, Santa Cruz, CA) in PBS containing $3 \% \mathrm{BSA}$ for $18-20 \mathrm{~h}$ at $4{ }^{\circ} \mathrm{C}$. After three washes with PBS, cells were incubated with goat anti-rabbit Texas Red-tagged secondary antibody at a dilution of $1: 500$ in PBS for $1 \mathrm{~h}$ at RT. Cells were then washed in PBS and further incubated with $0.5 \mu \mathrm{g} / \mathrm{ml}$ DAPI at RT for $30 \mathrm{~min}$. Subcellular localization of Nrf2 was observed under fluorescent microscope equipped with digital camera (IX71, Olympus, Japan). The fluorescent images were captured using appropriate filters.

\section{RT-PCR}

After the extraction of total RNA from the experimental group's cochlea with the use of Trizol (Invitrogen) according to the manufacturer's protocol, single-stranded cDNA was synthesized from total RNA. Then, PCR with Taq DNA polymerase (Takara, Takara Shuzo, Kyoto, Japan) was performed for 27 cycles using the following protocol: $95^{\circ} \mathrm{C}$ for $40 \mathrm{~s}, 58^{\circ} \mathrm{C}$ for $40 \mathrm{~s}$, and $72^{\circ} \mathrm{C}$ for $50 \mathrm{~s}$. The sequences of primers used for PCR amplification are as follows: GAPDH (forward, 5'-AAC GGG AAG CCC ATC ACC-3', and reverse, $5^{\prime}$-CAG CCT TGG CAG CAC CAG-3'); NQO-1 (forward, 5'-CAT TCT GAA AGG CTG GTT TGA-3', and reverse, 5'-CTA GCT TTG ATC TGG TTG TCA G-3'); GCLC (forward, 5'-ACA AGC ACC CCC GCT TCG GT-3', and reverse, 5'-CTC CAG GCC TCT CTC CTC CC-3'); GCLM (forward, 5'-ACC TGG CCT CCT GCT GTG TG-3', and reverse, 5'-GGT CGG TGA GCT GTG GGT GT-3'), GST $\mu$-1 (forward, 5'-CTC CCG ACT TTG ACA GAA GC-3', and reverse, 5'-CAG GAA GTC CCT CAA GTT TG-3'); and GSTA4 (forward, 5'-GCC AAG TAC CCT TGG TTG AA-3', and reverse, 5'-CAA TCC TGA CCA CCT CAA CA-3').

\section{Culture of the organ of Corti explants}

The organ culture procedure was similar to that described previously. ${ }^{51}$ Spague Dawley rat was sacrificed on postnatal day 2 (P2) and the cochlea was carefully dissected out. The stria vascularis and spiral ligament were dissected away leaving the organ of Corti. The middle turn of the cochlea was used for further analysis. Cochlea explants were treated with high glucose $(4.5 \mathrm{~g} / \mathrm{l})$ DMEM containing $10 \%$ FBS, $20 \mu \mathrm{M}$ cisplatin, $10 \mu \mathrm{M}$ flunarizine, $20 \mu \mathrm{M}$ CoPPIX, and $10 \mu \mathrm{M}$ SnPPIX and further incubated at $37^{\circ} \mathrm{C}$ in $5 \% \mathrm{CO}_{2}$ for $24 \mathrm{~h}$. Control sample in DMEM containing only serum was run concurrently with the experimental samples. At the end of the experiments, the culture was prepared for histological analysis. Specimen was fixed for $15 \mathrm{~min}$ in $2 \%$ paraformaldehyde in $0.1 \mathrm{M}$ phosphate buffer (pH 7.4) at RT. Specimen was rinsed in 0.1 M PBS, then incubated in $0.25 \%$ Triton X-100 for 2 min and immersed in TRITC-labeled phalloidin (Sigma P1951, 1: 100) in PBS for 20 min. After three washes with PBS, specimen was examined under fluorescence microscope with appropriate filters for TRITC (excitation: $510-550 \mathrm{~nm}$, emission: $590 \mathrm{~nm}$ ). 


\section{Statistical analysis}

Each experiment was performed at least three times, and all values are represented as means \pm S.D. of triplicates. One-way ANOVA was used to analyze a statistical significance of the results. Values of $P<0.05$ were considered as statistically significant.

\section{Acknowledgements}

This work was supported by the Korea Science \& Engineering Foundation (KOSEF) through the Vestibulocochlear Research Center (VCRC) at Wonkwang University in 2005.

\section{References}

1. Jaiswal AK (2004) Nrf2 signaling in coordinated activation of antioxidant gene expression. Free Radic. Biol. Med. 36: 1199-1207.

2. Huang HC, Nguyen T, Pickett CB (2002) Phosphorylation of Nrf2 at Ser-40 by protein kinase $C$ regulates antioxidant response element-mediated transcription. J. Biol. Chem. 277: 42769-42774.

3. Chan K, Han XD, Kan YW (2001) An important function of Nrf2 in combating oxidative stress: detoxification of acetaminophen. Proc. Natl. Acad. Sci. USA 98: 4611-4616.

4. Chan K, Kan YW (1999) Nrf2 is essential for protection against acute pulmonary injury in mice. Proc. Natl. Acad. Sci. USA 96: 12731-12736.

5. Cho HY, Jedlicka AE, Reddy SP, Kensler TW, Yamamoto M, Zhang LY, Kleeberger SR (2002) Role of NRF2 in protection against hyperoxic lung injury in mice. Am. J. Respir. Cell. Mol. Biol. 26: 175-182.

6. Lee JM, Calkins MJ, Chan K, Kan YW, Johnson JA (2003) Identification of the NF-E2-related factor-2-dependent genes conferring protection against oxidative stress in primary cortical astrocytes using oligonucleotide microarray analysis. J. Biol. Chem. 278: 12029-12038.

7. Leung L, Kwong M, Hou S, Lee C, Chan JY (2003) Deficiency of the Nrf1 and Nrf2 transcription factors results in early embryonic lethality and severe oxidative stress. J. Biol. Chem. 278: 48021-48029.

8. Ryter SW, Choi AM (2002) Heme oxygenase-1: molecular mechanisms of gene expression in oxygen-related stress. Antioxid. Redox. Signal. 4: 625-632.

9. Fram RJ (1992) Cisplatin and platinum analogues: recent advances. Curr. Opin. Oncol. 4: 1073-1079.

10. McAlpine D, Johnstone BM (1990) The ototoxic mechanism of cisplatin. Heart Res. 47: 191-203.

11. Rybak LP, Whitworth C, Somani S (1999) Application of antioxidants and other agents to prevent cisplatin ototoxicity. Laryngoscope 109: 1740-1744.

12. Santi CM, Cayabyab FS, Sutton KG, McRory JE, Mezeyova J, Hamming KS, Parker D, Stea A, Snutch TP (2002) Differential inhibition of T-type calcium channels by neuroleptics. J. Neurosci. 22: 396-403.

13. Kaminski Schierle GS, Hansson O, Brundin P (1999) Flunarizine improves the survival of grafted dopaminergic neurons. Neuroscience 94: 17-20.

14. So HS, Park C, Kim HJ, Lee JH, Park SY, Lee ZW, Kim HM, Kalinec F, Lim DJ, Park R (2005) Protective effect of T-type calcium channel blocker flunarizine on cisplatin-induced death of auditory cells. Heart Res. 204: 127-139.

15. Martin D, Rojo Al, Salinas M, Diaz R, Gallardo G, Alam J, De Galarreta CM, Cuadrado A (2004) Regulation of heme oxygenase-1 expression through the phosphatidylinositol 3-kinase/Akt pathway and the Nrf2 transcription factor in response to the antioxidant phytochemical carnosol. J. Biol. Chem. 279: 8919-8929.

16. Kietzmann T, Samoylenko A, Immenschuh S (2003) Transcriptional regulation of heme oxygenase-1 gene expression by MAP kinases of the JNK and p38 pathways in primary cultures of rat hepatocytes. J. Biol. Chem. 278: 17927-17936.

17. Shan Y, Pepe J, Lu TH, Elbirt KK, Lambrecht RW, Bonkovsky HL (2000) Induction of the heme oxygenase-1 gene by metalloporphyrins. Arch. Biochem. Biophys. 380: 219-227.

18. Hu CM, Chen YH, Chiang MT, Chau LY (2004) Heme oxygenase-1 inhibits angiotensin II-induced cardiac hypertrophy in vitro and in vivo. Circulation 110: 309-316.
19. Humes HD (1999) Insights into ototoxicity. Analogies to nephrotoxicity. Ann. NY Acad. Sci. 884: 15-18.

20. Kopke RD, Liu W, Gabaizadeh R, Jacono A, Feghali J, Spray D, Garcia P, Steinman H, Malgrange B, Ruben RJ, Rybak L, Van de Water TR (1997) Use of organotypic cultures of Corti's organ to study the protective effects of antioxidant molecules on cisplatin-induced damage of auditory hair cells. Am. J. Otol. 18: 559-571.

21. Watanabe KC, Jinnouchi K, Hess A, Michel O, Baba S, Yagi T (2002) Carboplatin induces less apoptosis in the cochlea of guinea pigs than cisplatin. Chemotherapy 48: 82-87.

22. Huang T, Cheng AG, Stupak H, Liu W, Kim A, Staecker H, Lefebvre PP, Malgrange B, Kopke R, Moonen G, Van De Water TR (2000) Oxidative stressinduced apoptosis of cochlear sensory cells: otoprotective strategies. Int. J. Dev. Neurosci. 18: 259-270.

23. Kharbanda S, Pandey P, Yamauchi T, Kumar S, Kaneki M, Kumar V, Bharti A, Yuan ZM, Ghanem L, Rana A, Weichselbaum R, Johnson G, Kufe D (2000) Activation of MEK kinase 1 by the c-Abl protein tyrosine kinase in response to DNA damage. Mol. Cell. Biol. 20: 4979-4989.

24. Kartalou M, Essigmann JM (2001) Recognition of cisplatin adducts by cellular proteins. Mutat. Res. 478: 1-21.

25. Feghali JG, Liu W, Van De Water TR (2001) L-n-acetyl-cysteine protection against cisplatin-induced auditory neuronal and hair cell toxicity. Laryngoscope 111: 1147-1155.

26. Jordan P, Carmo-Fonseca M (2000) Molecular mechanisms involved in cisplatin cytotoxicity. Cell. Mol. Life. Sci. 57: 1229-1235.

27. Davis CA, Nick HS, Agarwal A (2001) Manganese superoxide dismutase attenuates Cisplatin-induced renal injury: importance of superoxide. J. Am. Soc. Nephrol. 12: 2683-2690.

28. Alam J, Stewart D, Touchard C, Boinapally S, Choi AM, Cook JL (1999) Nrf2, a Cap'n'Collar transcription factor, regulates induction of the heme oxygenase-1 gene. J. Biol. Chem. 274: 26071-26078.

29. Venugopal R, Jaiswal AK (1996) Nrf1 and Nrf2 positively and c-Fos and Fra1 negatively regulate the human antioxidant response element-mediated expression of $\mathrm{NAD}(\mathrm{P}) \mathrm{H}$ :quinone oxidoreductase1 gene. Proc. Natl. Acad. Sci. USA 93: 14960-14965.

30. Moinova HR, Mulcahy RT (1999) Up-regulation of the human gammaglutamylcysteine synthetase regulatory subunit gene involves binding of Nrf-2 to an electrophile responsive element. Biochem. Biophys. Res. Commun. 261: 661-668.

31. Zipper LM, Mulcahy RT (2002) The Keap1 BTB/POZ dimerization function is required to sequester Nrf2 in cytoplasm. J. Biol. Chem. 277: 36544-36552.

32. Yu R, Chen C, Mo YY, Hebbar V, Owuor ED, Tan TH, Kong AN (2000) Activation of mitogen-activated protein kinase pathways induces antioxidant response element-mediated gene expression via a Nrf2-dependent mechanism. J. Biol. Chem. 275: 39907-39913.

33. Kataoka K, Fujiwara KT, Noda M, Nishizawa M (1994) MafB, a new Maf family transcription activator that can associate with Maf and Fos but not with Jun. Mol. Cell. Biol. 14: 7581-7591.

34. Itoh K, Chiba T, Takahashi S, Ishii T, Igarashi K, Katoh Y, Oyake T, Hayashi N, Satoh K, Hatayama I, Yamamoto M, Nabeshima Y (1997) An Nrf2/small Maf heterodimer mediates the induction of phase II detoxifying enzyme genes through antioxidant response elements. Biochem. Biophys. Res. Commun. 236: 313-322.

35. Plas DR, Thompson CB (2005) Akt-dependent transformation: there is more to growth than just surviving. Oncogene 24: 7435-7442.

36. Ruggero D, Sonenberg N (2005) The Akt of translational control. Oncogene 24: 7426-7434.

37. Abdul-Ghani R, Serra V, Gyorffy B, Jurchott K, Solf A, Dietel M, Schafer R (2005) The PI3K inhibitor LY294002 blocks drug export from resistant colon carcinoma cells overexpressing MRP1. Oncogene Advance online publication 14 November 2005; doi: 10.1038/sj.onc.1209201.

38. Goswami A, Burikhanov R, de Thonel A, Fujita N, Goswami M, Zhao Y, Eriksson JE, Tsuruo T, Rangnekar VM (2005) Binding and phosphorylation of par-4 by akt is essential for cancer cell survival. Mol. Cell 20: 33-44.

39. Shimizu H, Takahashi T, Suzuki T, Yamasaki A, Fujiwara T, Odaka Y, Hirakawa M, Fujita $H$, Akagi $R(2000)$ Protective effect of heme oxygenase induction in ischemic acute renal failure. Crit. Care Med. 28: 809-817.

40. Maines MD (1988) Heme oxygenase: function, multiplicity, regulatory mechanisms, and clinical applications. FASEB J. 2: 2557-2568. 
41. Hartsfield CL, Alam J, Choi AM (1999) Differential signaling pathways of HO-1 gene expression in pulmonary and systemic vascular cells. Am. J. Physiol. 277: L1133-L1141.

42. Lee PJ, Camhi SL, Chin BY, Alam J, Choi AM (2000) AP-1 and STAT mediate hyperoxia-induced gene transcription of heme oxygenase-1. Am. J. Physiol. Lung. Cell. Mol. Physiol. 279: L175-182.

43. Owuor ED, Kong AN (2002) Antioxidants and oxidants regulated signal transduction pathways. Biochem. Pharmacol. 64: 765-770.

44. Alam J, Wicks C, Stewart D, Gong P, Touchard C, Otterbein S, Choi AM, Burow ME, Tou J (2000) Mechanism of heme oxygenase-1 gene activation by cadmium in MCF-7 mammary epithelial cells. Role of p38 kinase and Nrf2 transcription factor. J. Biol. Chem. 275: 27694-27702.

45. He CH, Gong P, Hu B, Stewart D, Choi ME, Choi AM, Alam J (2001) Identification of activating transcription factor 4 (ATF4) as an Nrf2-interacting protein. Implication for heme oxygenase-1 gene regulation. J. Biol. Chem. 276: 20858-20865.

46. Ishii $T$, Itoh $K$, Takahashi $S$, Sato $H$, Yanagawa $T$, Katoh $Y$, Bannai $S$, Yamamoto M (2000) Transcription factor Nrf2 coordinately regulates a group of oxidative stress-inducible genes in macrophages. J. Biol. Chem. 275: 16023-16029.

47. Gong P, Hu B, Stewart D, Ellerbe M, Figueroa YG, Blank V, Beckman BS, Alam J (2001) Cobalt induces heme oxygenase-1 expression by a hypoxiainducible factor-independent mechanism in Chinese hamster ovary cells: regulation by Nrf2 and MafG transcription factors. J. Biol. Chem. 276: 27018-27025.

48. Kalinec GM, Webster $P$, Lim DJ, Kalinec $F$ (2003) A cochlear cell line as an in vitro system for drug ototoxicity screening. Audiol. Neurootol. 8: 177-189.

49. Rivolta MN, Grix N, Lawlor P, Ashmore JF, Jagger DJ, Holley MC (1998) Auditory hair cell precursors immortalized from the mammalian inner ear. Proc. R. Soc. Lond. B. Biol. Sci. 265: 1595-1603.

50. Balla G, Jacob HS, Balla J, Rosenberg M, Nath K, Apple F, Eaton JW, Vercellotti GM (1992) Ferritin: a cytoprotective antioxidant strategem of endothelium. J. Biol. Chem. 267: 18148-18153.

51. Zheng JL, Gao WQ (1996) Differential damage to auditory neurons and hair cells by ototoxins and neuroprotection by specific neurotrophins in rat cochlear organotypic cultures. Eur. J. Neurosci. 8: 1897-1905. 